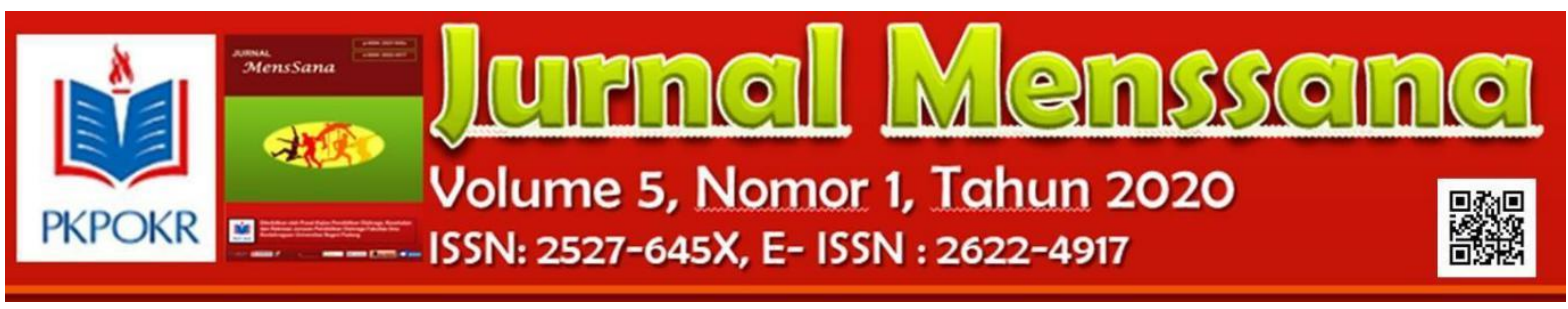

\title{
Pola Pengembangan Wisata Olahraga Rumpit Bike And Adventure Di Kabupaten Banjarnegara
}

\author{
Indra Jati Kusuma ${ }^{1}$, Panuwun Joko Nurcahyo ${ }^{2}$, Bayu Suko Wahono ${ }^{3}$, Rifqi Festiawan ${ }^{4}$ \\ ${ }^{1,2,3,4}$ Program Studi Pendidikan Jasmani, Universitas Jenderal Soedirman \\ Email : rifqi.festiawan@unsoed.ac.id
}

Menerima: 20 April 2020; Revisi: 28 April 2020; Diterima: 29 April 2020

https://doi.org/10.24036/jm.v\%vi\%i.133

\begin{abstract}
This study aims to determine the pattern of developing sport and adventure tourism rumpit bike in Banjarnegara Regency. This research is a qualitative descriptive study. Data collection techniques were obtained through observation, focus group discussion, interviews and documentation. Determination of the sample is obtained by purposive sampling technique. Validity test uses data triangulation and data analysis techniques use interactive analysis. The results of this study are: 1) Tourism development efforts undertaken are: a) Formation of working groups, b) Arrangement of hill clumps, c) Cooperating with youth leaders, d) Expanding networks with communities, e) Utilization of social media, e) Making photo spots , f) Imposing the price of admission, 2) Supporting and inhibiting factors are: Supporters: a) There is an up-to-date spot for photos b) free bicycle lending, c) There are places with interesting natural scenery, d) Potential for developing "down" bikes hill ". The obstacles are: a) Sources of funds, $b$ ) The location is far from water sources, c) The access road to the location is inadequate, d) Some areas have started to be damaged, 3) Potential: This sports tourism can be developed into a medium of physical education learning because: a) Students use it as a camping ground, b) It is used as an outbound place, c) Encourages student independence through nature, d) fosters a culture of cooperation. With these results, it can be concluded that the pattern of developing sport and adventure tourism rumpit bike and implemented through three aspects, namely development efforts, inhibiting and supporting factors as well as the potential for development.
\end{abstract}

Keywords: Development Pattern; Rumpit Bike Park and Adventure; Sport Recreation; Sport Tourism

\section{Abstrak}

Penelitian ini bertujuan untuk mengetahui pola pengembangan wisata olahraga rumpit bike and adventure di Kabupaten Banjarnegara. Penelitian ini merupakan penelitian deskriptif kualitatif. Teknik pengumpulan data diperoleh melalui observasi, focus group discusion, wawancara dan dokumentasi. Penentuan sampel diperoleh dengan teknik purposive sampling. Uji validitas menggunakan trianggulasi data dan teknik analisa data menggunakan analisa interaktif. Hasil penelitian ini adalah: 1) Upaya pengembangan wisata yang dilakukan adalah: a) Pembentukan kelompok kerja, b) Penataan bukit rumpit, c) Menggandeng tokoh pemuda, d) Meluaskan jaringan dengan komunitas, e) Pemanfaatan sosial media, e) Pembuatan spot foto, f) Memberlakukan harga tiket masuk, 2) Faktor pendukung dan penghambatnya adalah: Pendukung: a) Ada tempat spot foto yang terkini b) peminjaman sepeda gratis, c) Ada tempat dengan pemandangan alam yang menarik, d) Potensial untuk pengembangan sepeda "down hill". Penghambatnya: a) Sumber dana, b) Lokasinya jauh dari sumber air, c) Akses jalan menuju lokasi belum memadai, d) Beberapa area sudah mulai rusak, 3) Potens: Wisata olahraga ini dapat dikembangkan menjadi media pembelajaran pendidikan jasmani karena: a) Pelajar menggunakan

This work is licensed by Lisensi Creative Commons Atribusi-BerbagiSerupa 4.0 Internasional, Link ARCHIVES: $\underline{\text { http://menssana.ppj.unp.ac.id/index.php/jm/issue/view/9 }}$ 
sebagai tempat berkemah, b) Digunakan sebagai tempat outbond, c) Mendorong kemandirian pelajar melalui alam, d) menumbuhkan budaya kerjasama. Dengan hasil tersebut, dapat disimpulkan bahwa pola pengembangan wisata olahraga rumpit bike and adventure terlaksana melalui tiga aspek yaitu upaya pengembangan, faktor penghambat dan pendukung serta potensi pengembangan.

Kata Kunci: Pola Pengembangan; Rumpit Bike Park and Adventure; Olahraga Rekreasi; Wisata Olahraga

\section{PENDAHULUAN}

Dalam Undang-Undang Republik Indonesia No 3 tahun 2005 tentang sistem keolahragaan nasional disebutkan bahwa olahraga dibagi menjadi tiga yaitu olahraga pendidikan, olahraga prestasi dan olahraga rekreasi. Pendidikan dan kesehatan merupakan dua hal yang dapat dikatakan saling berkaitan (Festiawan et al., 2019), sedangkan olahraga rekreasi adalah olahraga yang dilakukan oleh masyarakat dengan kegemaran dan kemampuan yang tumbuh dan berkembang sesuai dengan kondisi dan nilai budaya masyarakat setempat.

Tujuannya untuk kesehatan, kebugaran, dan kesenangan. Pembinaan dan pengembangannya dilaksanakan oleh pemerintah daerah, dan masyarakat dengan membangun dan memanfaatkan potensi sumber daya, prasarana dan sarana olahraga rekreasi.

Olahraga rekreasi yang bersifat tradisional dilakukan dengan menggali, mengembangkan, melestarikan, dan memanfaatkan olahraga tradisional yang ada dalam masyarakat dengan memperhatikan prinsip mudah, murah, menarik, manfaat, dan massal.

Hal ini dilaksanakan sebagai upaya menumbuh kembangkan sanggar-sanggar dan mengaktifkan perkumpulan olahraga dalam masyarakat, serta menyelenggarakan festival olahraga rekreasi yang berjenjang dan berkelanjutan. Apabila hal ini bisa dikembangkan dapat dijadikan sarana melestarikan budaya sesuai dengan kearifan lokal masing-masing daerah.

Sport is an attractive tool for destinations to develop and market their tourism product (Ziakas \& Boukas, 2012). Saat ini sektor pariwisata sebagai salah satu kegiatan industri pelayanan dan jasa, diharapkan menjadi andalan dalam rangka meningkatkan pemasukan disetiap daerah.

Hal ini dapat memberikan harapan bahwa pariwisata dapat berkembang bilamana wisatawan nusantara dapat diaktifkan lagi. Selain menghasilkan pendapatan bagi negara, pengembangan obyek wisata juga untuk menciptakan lapangan kerja baru. Dengan ditetapkannya Undang-Undang No. 32 Tahun 2004 yang menjadi landasan berlangsungnya sistem desentralisasi, pelaksanaan desentralisasi dan otonomi daerah yang dilaksanakan di seluruh daerah di Indonesia.

Dalam rangka mengembangkan wisata di kabupaten banjarnegara telah diadakan festival yang diselenggarakan dalam sekala regional, Dieng Culture Festival (DCF) sebagai agenda tahunan yang selalu dipromosikan Dinas Pariwisata dan Kebudayaan (Dinparbud) Banjarnegara.

Berdasarkan data dari Dinparbud Banjarnegara, secara keseluruhan rangkaian acara DCF dimulai tanggal 3 sampai dengan 5 Agustus 2018, dengan agenda bersih-bersih kawasan Dieng, festival tumpeng, festival bunga, hingga festival domba batur.

Menurut Aprilianto (Ketua Festival), tumpeng merupakan satu syarat dalam ruwat rambut gimbal yang menjadi ritual khas di DCF. Selain itu, ada konser musik Jazz Atas Awan yang di gelar di komplek Candi Arjuna Dieng. Berbagai musisi jazz dalam dan luar negeri, dipastikan hadir menghangatkan suasana DCF 2018. Sementara untuk festival lampion, masih menjadi agenda tetap dalam DCF. Ribuan lampion ini diterbangkan malam hari, usai Akustik Atas Awan (Firmansyah, 2018).

Pada kegiatan DCF terdapat expo dari desa wisata unggulan yang ada di Banjarnegara, diantaranya adalah desa wisata Salamerta, yang menampilkan wisata olahraga rumpit bike park and adventure. Disamping menampilkan wisata olahraga juga menyajikan kuliner Wedang Rempah dengan bahan utama Kayu Secang sebagai minuman khas pendukung wisata.

Pengunjung DCF yang datang ke stan desanya, diharapkan tertarik untuk datang langsung ke objek wisata yang ditawarkan (sumber: Prasetyo, Ketua Pokdarwis). Bukit rumpit yang dikelola Pokdarwis Desa Salamerta bekerjasama dengan Perhutani, merupakan tempat yang cocok dijadikan alternatif tujuan wisata olahraga bagi penggemar sepeda dan petualangan alam.

Hal ini juga mempunyai potensi untuk dijadikan tempat yang mendukung dalam pembelajaran pendidikan jasmani (penjas) di sekolah. Dalam pembelajaran penjas, ada materi pendidikan luar sekolah yang meliputi: piknik/karyawisata, pengenalan lingkungan, berkemah, menjelajah dan mendaki gunung.

Pendidikan luar kelas pada dasarnya 
merupakan pendidikan lintas bidang studi, karena di dalam kegiatannya meliputi seni, ilmu alam, pendidikan jasmani dan home economic.

Pendidikan luar kelas merupakan salah satu dimensi dalam pendidikan jasmani, di mana melalui program kegiatan ini diharapkan konsep diri siswa dapat dibentuk. Pengalaman memanjat, merangkak, bergelantungan, dan berayun di alam bebas, yang merupakan bagian dari progam petualangan akan mampu meningkatkan rasa percaya diri siswa. Pengalaman semacam, ini dapat memenuhi kebutuhan psikis anak akan rasa berhasil mengatasi rintangan (Rahayu, 2009.

Dari hasil survei awal dengan pengurus pokdarwis, tingkat kunjungan rombongan guru dan pelajar ke rumpit bike park and adventure untuk djadikan tempat pembelajaran penjas masih belum optimal. Hal ini dikarenakan belum banyak mendapatkan fokus perhatian dari pengelola, karena persiapan yang masih minim sehingga dari sisi pengemasan maupun promosi kurang maksimal.

Disamping itu pengunjung masih didominasi dari masyarakat umum dan komunitas hobi sepeda. Sehingga untuk diangkat menjadi wisata olahraga sebagai tempat pembelajaran dan media pendidikan jasmani perlu promosi serta partisipasi yang lebih, baik dari segi kemasan maupun ruang lingkup pengunjung. Padahal apabila wisata olahraga ini dikembangkan, diharapkan mampu menambah daya tarik kunjungan pada destinasi wisata dikabupaten Banjarnegara secara lebih luas, yang akan berimbas pada banyak faktor, pada akhirnya dapat meningkatkan pendapatan asli daerah.

Dari latar belakang diatas maka sangat perlu dilakukan kajian-kajian dengan dilakukan penelitian terkait Pola Pengembangan Wisata Olahraga Rumpit Bike Park And Adventure di Kabupaten Banjarnegara. Hal tersebut sangat penting untuk diteliti karena wisata olahraga apabila dikemas dengan pola pengembangan yang tepat dapat menarik jumlah wisatawan yang berkunjung, sehingga pendapatan asli daerah akan meningkat.

\section{METODE \\ Desain Penelitian}

Penelitian ini menggunakan pendekatan deskriptif kualitatif (Thomas, et. al., 2001). Tujuan dari penelitian deskriptif untuk mempresentasikan informasi demografis mengenai responden dan mendiskusikan isu-isu yang muncul (Bandur, 2019). Sumber data penelitian meliputi data primer yaitu;

1. Responden yang membidangi pariwisata pada dinas pemuda olahraga dan pariwisata kabupaten purbalingga, bidang kebudayaan dinas pendidikan kabupaten purbalingga dan, panitia, pengelola serta peserta even festival.

2. Sumber data sekunder melalui dokumendokumen yang berkaitan dengan obyek penelitian, catatan-catatan penunjang, literatur, buku-buku perpustakaan, dokumentasi, arsip-arsip dan keteranganketerangan lain yang berhubungan dengan masalah penelitian yang digunakan sebagai pendukung dari data primer. Bagian metode ini memuat jenis penelitian, subjek penelitian, instrumen pengumpulan data, dan analisis data.

\section{Populasi dan Sampel}

Populasi dalam penelitian ini adalah seluruh pengelola wisata olahraga Rumpit Bike Park and Adventure yang tergabung dalam Kelompok Sadar Wisata Desa Salamerta Mandiraja Banjarnegara. Sedangkan sampel penelitian diambil dengan menggunakan teknik (purposive sampling) dengan kriteria; 1) Informan dianggap mengetahui informasi dan masalah secara mendalam, 2) Terlibat dalam proses pelaksanaan kegiatan, 3) Dapat dipercaya sebagai sumber data. 4) Menjadi pengelola kelompok kerja sadar wisata.

\section{Teknik Pengumpulan Data}

Teknik pengambilan data dilakukan dengan observasi, focus group discusion, wawancara dan dokumentasi (direkam melalui video). Validitas data di lakukan secara triangulasi sumber data. Triangulasi adalah teknik pemeriksaan keabsahan yang memanfaatkan sesuatu yang lain di luar data itu untuk keperluan pengecekan atau sebagai pembanding terhadap data itu (Moleong, 2002: 178).

\section{Analisis Data}

Metode analisis dalam penelitian ini menggunakan model analisis interaktif. Model analisis interaktif terdiri dari tiga alur kegiatan yang terjadi secara bersamaan, yaitu: reduksi data, penyajian data, dan penarikan kesimpulan atau verifikasi (Miles, 1992: 16). 1)

1. Reduksi Data; diartikan sebagai proses pemilihan, pemusatan perhatian pada penyederhanaan dan informasi data kasar yang muncul dari catatan-catatan tertulis di lapangan. Reduksi data berlangsung secara terus menerus selama penelitian berlangsung. Antisipasi akan adanya reduksi data sudah tampak ketika penelitian memutuskan kerangka konseptual wilayah penelitian, permasalahan penelitian, dan pendekatan pengumpulan data yang dipilih. Tahapan selanjutnya membuat ringkasan, mengkode, menelusuri tema, membuat gugus, membuat partisi, dan menulis memo. Reduksi data ini 
terus berlanjut sampai penulisan penelitian selesai.

2. Penyajian Data; yang dikumpulkan dibatasi hanya sebagai sekumpulan informasi tersusun yang memberikan kemungkinan adanya penarikan kesimpulan dan pengambilan tindakan. Penyajian yang dimaksud meliputi berbagai jenis grafik, bagan, dan bentuk lainnya. Dirancang untuk menggabungkan informasi yang tersusun dalam suatu bentuk yang padu, mudah didapat, sehingga penganalisisan dalam melihat apa yang terjadi, dan menentukan apakah penarikan kesimpulan yang benar sudah dapat dilakukan ataukah terus melangkah melakukan analisis yang berguna.

3. Penarikan kesimpulan; dimulai dari pengumpulan data, pendefinisian suatu konsep mencatat keteraturan, pola-pola, penjelasan, konfigurasi-konfigurasi yang mungkin, alur sebab-akibat, dan proposisi kemudian menjadi keterangan yang lebih rinci.

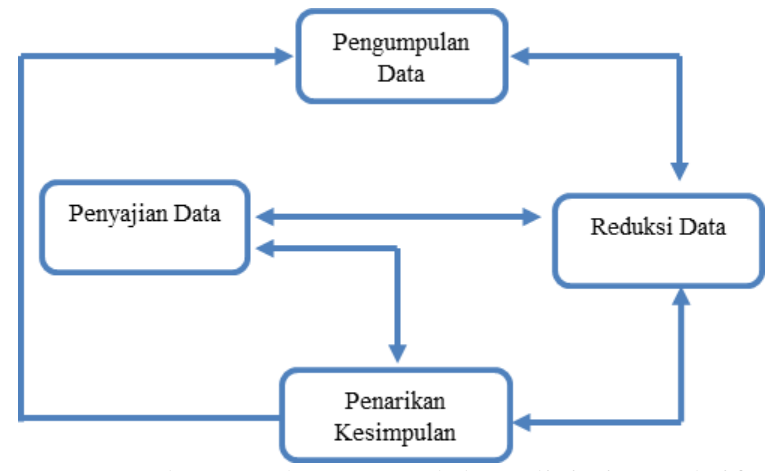

Gambar 1. Skema model analisis interaktif (Sumber: Matthew B. Miles dan A. Michael Huberman, dalam Demartoto, A (2008)

\section{HASIL DAN PEMBAHASAN}

Penelitian ini dimulai dari pembagian jadwal observasi, focus group discusion, wawancara dan dokumentasi (direkam melalui video). Pada penelitian ini dilakukan pengambilan data, dengan sampel yaitu kelompok kerja pemuda desa selamarta kecamatan mandiraja, yang tergabung dalam Kelompok Sadar Wisata (Pokdarwis), dengan ketua tim Slamet Haryono.

Bapak Slamet Haryono merupakan salah satu tokoh penggerak pemuda didesa salamerta. Dengan perjalanan karirnya yang variatif, yaitu pernah bekerja sebagai operator alat berat perusahaan tambang batubara dikalimantan, bekerja sebagai sales marketing mitsubhisi motor, anggota Badan Pertimbangan Desa (BPD) Salamerta, Anggota Karang Taruna hingga saat ini.

Dengan latar belakang pengalaman tersebut
Slamet Haryono terlatih untuk memimpin kelompok sadar wisata di desa salamerta. Wawancara berikutnya dilakukan kepada Bapak Kardiman. Beliau bertugas dalam kelompok kerja sebagai wakil ketua, posisi ini teramat penting sebagai kepanjangtanganan apabila ketua berhalangan hadir dalam berbagai pertemuan, dengan para pemangku kepentingan.

Selain itu juga telah dilakukan wawancara kepada Bapak Sarwo. Beliau merupakan tokoh penggerak pemuda yang bertugas sebagai bendahara kelompok kerja, tentunya posisi ini sangat penting untuk mengatur aliran masuk dan keluarnya keuangan.

Baik bapak Bapak Sarwo maupun Bapak Kardiman, keduanya sehari-hari berprofesi sebagai tukang batu. Dengan profesi keduanya yang sudah terbiasa dalam hal pembangunan fisik, sangat membantu sekali dalam mendukung perencanaan dan pelaksanaan kegiatan pembangunan baik bersifat semipermanen maupun permanen yang diperlukan dalam keberlangsungan sarana dan prasarana yang ada di bukit rumpit.

Setelah melakukan wawancara kemudian penulis melakukan focus group discusion, dengan mengumpulkan kelompok kerja bukit rumpit tim desa selamerta Data diambil dengan wawancara dan focus group discusion, kemudian dilakukan perekaman. Kemudian tahap berikutnya masuk editing, reduksi data dan pengambilan kesimpulan. Berdasarkan telaah hasil pengambilan data diatas, berikut disajikan informsi dari narasumber, hal ini disesuaikan dengan pertanyaan penelitian yang telah diajukan sebelumnya:

1. Bagaimana Pengembangan wisata olahraga Rumpit Bike Park And Adventure yang dilakukan oleh Kelompok Sadar Wisata Salamerta di Banjarnegara?

Pembentukan kelompok kerja di bukit rumpit dirintis mulai tahun 2016, aktivitas kerja dimulai dengan kerja bakti, hal ini dilakukan untuk menata bukit rumpit lebih menarik dengan mengumpulkan para pemuda. Ada tokoh pemuda asli desa salamerta yang tergabung di HIPMI (Himpunan Pengusaha Muda Indonesia) mulai membantu memberdayakan pemuda.

Pertemuannya dengan komunitas sepeda, memulai awal perjalanan ide pembuatan jalur sepeda di bukit ini. Dengan diskusi dan tukar pendapat akhirnya lewat kelompok tersebut tercetuslah ide untuk memberi nama "Rumpit Bike Park". Perjalanan berikutnya dimulai awal tahun 2017 dengan menyebarkan informasi melalui media sosial.

Awal bulan Maret tahun 2017, uji coba 
jalur untuk sepeda sudah mulai bisa ditembus dari tempat loading, rest area sampai dengan tempat finis. Pemuda desa terlibat aktif bergotong royong dalam kegiatan pembuatan jalur ini, Para pemuda tersebut sebagaian besar berprofesi sebagai pekerja lepas.

Melalui informasi antar komunitas sepeda, awal mula pembukaan jalur, dalam tahap uji coba ini setiap minggu sudah mulai ramai dikunjungi. Pada tahap ini dalam satu hari pengunjumg bisa mencapai 60 orang.

Setelah itu kemudian dilanjutkan dengan kerja bakti pembuatan "spot foto" untuk menambah daya tarik tempat jalur sepeda terutama dipusatkan ditempat rest area. Setelah dipandang mencukupi untuk dibuka secara umum, pada waktu itu mulai dikenakan dengan harga tiket tarif masuk lima ribu rupiah.

2. Faktor pendukung dalam wisata olahraga rumpit bike park and adventure di Banjarnegara?

Dalam perjalanan waktu, tentunya dalam pengelolaan tempat wisata olahraga ini terdapat beberapa faktor pendukung, yang diantaranya dapat dianalisa sebagai berikut.

a. Adanya tempat spot foto yang baru untuk selfi dan diedarkan dimedia sosial (intagram, facebook) hal ini memunculkan rasa penasaran para pengunjung untuk tertarik datang,

b. Pada setiap hari minggu dipenuhi para wisatawan yang ingin bertemu dengan komunitas sepeda untuk meminjam sepeda beserta aparelnya dan komunitas sepeda juga berkepetingan untuk berswafoto maupun foto bersama

c. Ada tempat dek khusus dengan view (pemandangan dan bentang alam yang menarik) untuk berswafoto dengan menggunakan sepeda baik yang dipinjam dari komunitas maupun dari pengelola

d. Jalur yang telah ada, sangat potensial untuk pengembangan sepeda "down hill"'

3. Apakah Faktor penghambat dalam wisata olahraga rumpit bike park and adventure di Banjarnegara?

Dalam hal ini juga tentunya dalam pengelolaan tempat wisata olahraga ini terdapat beberapa faktor penghambat, yang diantaranya dapat dianalisa sebagai berikut:

a. Dana yang mulai terkumpul sebagai hasil dari usaha jasa pariwisata, sedikit demi sedikit mulai berkurang karena terpakai oleh anggota yang meminjam untuk kebutuhan mendesak, dan tidak ada kepastian dalam hal pengembaliannya

b. Lokasi tempat tersebut jauh dari sumber air yang melimpah, sehingga keinginan pengelola untuk menambahkan spot berbasis wisataa air, belum bisa dikembangkan

c. Akses jalan menuju lokasi bukit rumpit untuk wisata umum, belum memadai untuk dilewati sarana transportasi secara nyaman, terlebih pada musim hujan jalan akan terasa licin

d. Beberapa area yang digunakan sebagai spot foto, sudah mulai terlihat rusak karena masih terbuat dari bahan semi permanen dengan material kayu dan bambu, sehingga perlu pengadaan pembaharuan dan perawatan yang intensif.

4. Apakah wisata olahraga rumpit bike park and adventure dapat dikembangkan menjadi media pembelajaran pendidikan jasmani?

Dalam hal ini juga tentunya dalam pengelolaan tempat wisata olahraga ini terdapat beberapa kemungkinan untuk dikembangkan sebagai media pembelajaran penjas, yang diantaranya dapat dianalisa sebagai berikut.

a. Pada waktu itu sudah mulai dikunjungi para siswa dari berbagai sekolah menengah kejuruan (SMK) diantaranya dari SMK Himpunan Kerukunan Tani Indonesia (HKTI) Purwareja Klampok, SMKN 1 Mandiraja, SMK Bina Mandiri Mandiraja dan beberapa Sekolah yang lain, untuk digunakan sebagai tempat kegiatan berkemah. Tempat yang digunakan berkemah yaitu di rest area

b. Bukit rumpit selain untuk berkemah, juga digunakan para siswa dari berbagai sekolah untuk digunakan sebagai tempat out bond. Hal ini bisa diselenggarakan, karena bukit rumpit dengan kontur perbukitan dengan kemiringan 26-55 derajat, terdapat pepohonan pinus cemara dan berbagai vegetasi khas perbukitan

c. Dengan view dan bentang alam serta pemandangan yang indah di bukit rumpit, pelajar yang melakukan kemah maupun kegiatan outbond, diajak untuk tidak tergantung dengan peralatan yang serba elektronik dan instan. Hal ini dapat mendorong kemandirian pelajar dengan mengenal alam lebih dekat. Sehingga diharapkan lebih memiliki rasa syukur terhadap karunia tuhan dan budaya saling 
bekerjasama antar individu maupun kelompok terbentuk. Pengalaman semacam, ini diharapkan bisa memenuhi kebutuhan psikis pelajar akan rasa berhasil mengatasi rintangan

Dengan mempertimbangkan hal tersebut diatas penulis membuat rekaman video profil bukit rumpit (dimulai perjalanan dari pintu masuk pertama sampai dengan tempat parkir dengan jarak sepanjang 350 meter dengan tingkat kemiringan 26-35 derajat, diarea sepanjang jalan utama ini masih dijumpai banyak rumah warga, dengan tanaman buah pisang dan pohon ketela, kontur jalan diperkeras dengan betong cor dan sebagian batu.

Kemudian dari tempat area parkir sampai ke pintu gerbang berikutnya sepanjang 250 meter, dengan kemiringan 36-45 derajat. Pada araea sepanjang jalur utama hanya dijumpai 3 rumah penduduk, dengan tanaman pohon ketela dan pohon bambu serta pohon buah lainnya. Kontur jalan sebagian besar diperkeras dengan batu.

Selanjutnya dari tempat pintu gerbang utama sampai ke rest area dan puncak bukit, dengan menempuh jarak 900 meter, dengan tingkat kemiringan 46-55 derajat. Pada area sepanjang jalan utama ini tanaman yang dijumpai seperti pohon pinus dan pohon keras lainnya, kontur jalan belum ada pengerasan dari batu.

Kemudian penulis menganalisa video tersebut dengan membandingkan beberapa literatur. Literatur yang digunakan terkait referensi berupa, video dan buku teks penggunaan prasarana aktivitas luar kelas, bagi pelajar yang dapat digunakan sebagai media pembelajaran.

\section{SIMPULAN}

Setelah melalui tahapan penelitian, pada tahap ini dapat disimpulkan bahwa:

1. Pengembangan wisata olahraga Rumpit Bike Park and Adventure yang dilakukan oleh Kelompok Sadar Wisata Salamerta adalah: a). Pembentukan kelompok kerja, b) Penataan bukit rumpit lebih menarik c) Menggandeng tokoh pemuda asli desa salamerta yang tergabung di Himpunan Pengusaha Muda Indonesia (HIPMI) d) Meluaskan jaringan dengan komunitas sepeda, e) Menyebarkan informasi melalui media sosial. e) Kerja bakti pembuatan "spot foto" ditempat rest area. f) Memberlakukan harga tiket tarif masuk lima ribu rupiah.

2. Faktor pendukung dan penghambat dalam wisata olahraga rumpit bike park and adventure adalah:

a. Faktor Pendukung

Adanya tempat spot foto yang baru untuk selfi dan diedarkan dimedia sosial (intagram, facebook). Pada setiap hari minggu para wisatawan bisa bertemu dengan komunitas sepeda untuk meminjam sepeda beserta aparelnya untuk berswafoto. Ada tempat dek khusus dengan view (pemandangan dan bentang alam yang menarik) untuk berswafoto dengan menggunakan sepeda baik yang dipinjam dari komunitas maupun dari pengelola. Jalur yang ada, sangat potensial untuk pengembangan sepeda "down hill".

b. Faktor Penghambat:

Dana yang terkumpul sedikit demi sedikit mulai berkurang karena terpakai oleh anggota yang meminjam untuk kebutuhan mendesak. Lokasinya jauh dari sumber air yang melimpah. Akses jalan menuju lokasi untuk wisata umum, belum memadai untuk dilewati sarana transportasi secara nyaman, terlebih pada musim hujan. Beberapa area yang digunakan sebagai spot foto, sudah mulai terlihat rusak, terbuat dari bahan semi permanen (kayu dan bambu).

c. Wisata olahraga rumpit bike park and adventure dapat dikembangkan menjadi media pembelajaran pendidikan jasmani karena Para pelajar menggunakan sebagai tempat kegiatan berkemah,selain itu digunakan sebagai tempat out bond. Kemudian, melalui wisata ini dapat mendorong kemandirian pelajar dengan mengenal alam lebih dekat, dan pelajar lebih bersyukur karunia tuhan dan budaya saling bekerjasama antar individu maupun kelompok terbentuk.

\section{DAFTAR PUSTAKA}

Azhar, A. (2008). Media Pembelajaran. Meedia Pembelajaran. https://doi.org/media pembelajaran

Demartoto, A. (2008). Laporan Penelitian Strategi Pengembangan Obyek Wisata Pedesaan Oleh Pelaku Wisata Di Kabupaten Boyolali. Surakarta:UNS

Festiawan, R., Ngadiman, N., Kusuma, I. J., Nurcahyo, P. J., \& Kusnandar, K. (2019). Pengembangan Model Pembelajaran Pendidikan Jasmani Berbasis Games, Education, and Visualisation (GEV) Untuk Meningkatkan Pengetahuan Kesehatan Reproduksi Remaja. Jendela Olahraga, 4(2), 13-25. https://doi.org/10.26877/jo.v4i2.3678

Firmansyah, 2018. Rangkaian Dieng Culture Festival 2018, dari Bersih-Bersih Hingga 
Beragam Festival. (Online). (https://satelitpost.com). diakses 28 November 2018.Nurmadiah, N. (2016). MEDIA PENDIDIKAN. Al-Afkar: Jurnal Keislaman \& Peradaban. https://doi.org/10.28944/afkar.v5i1.109

Giriwijoyo,S.,Sidik,D.Z. (2012). Ilmu Kesehatan Olahraga. Bandung: PT. Remaja Rosdakarya

Ngadiman, N., Kusuma, I. J., \& Festiawan, R. Sport Development Index of Banyumas Regency. Jurnal Pendidikan Jasmani Dan Olahraga, 4(2), 193-197.

Pendit, S Nyoman,. (1994). Ilmu Pariwisata Sebuang Pengantar Perdana, Jakarta: PT Pradnya Paramita.

Setiawati, E.,(2018). Blog Tempat Wisata Terkenal Dengan Keindahannya. (Online). (http://esisetiawati.blogspot.com/2018/02/te mpat-wisata-yang-ada-di-mandiraja.html). diakses 28 November 2018.

Suratmin. (2018). Pengantar Olahraga Rekreasi dan Olahraga Pariwisata. Depok: Rajawali Pers.

Undang-Undang Nomor 9 Tahun Tentang Kepariwisataan. (1990). Jakarta: Kementerian Pariwisata.

Undang-Undang Republik Indonesia No 3 Tentang Sistem Keolahragaan Nasional. (2005). Jakarta: Kemenpora.

Umar. (2014). Peran dan Fungsinya dalam Pembelajaran. Al-Afkar: Jurnal Keislaman \& Peradaban.

Ziakas, V., \& Boukas, N. (2012). A neglected legacy. International Journal of Event and Festival Management, 3(3), 292-316. 